\title{
Digital Image Processing Applied to Seed Purity Test
}

\author{
Ms. Mrinal Sawarkar ${ }^{1}$, Dr. S.V.Rode ${ }^{2}$ \\ Student, Department of Electronics \& Telecommunication, Sipna College of Engineering, Amravati, [M.S.], India ${ }^{1}$ \\ Professor, Department of Electronics \& Telecommunication, Sipna College of Engineering, Amravati, [M.S.], India ${ }^{2}$
}

\begin{abstract}
In this paper we used digital image processing techniques for purity test of various seeds. Physical purity analysis tells us the proportion of pure seed component in the seed lot. The computer software which can predict seed image for seed lot by using digital image processing techniques is developed. Due to the advance of camera technology, people can take digital pictures easily in any places and any time by a camera or by a mobile phone device. Moreover, it is easy to transform and process by using a computer system. Thus, this project employs a digital camera to capture the image. This paper studies various digital image processing techniques which reduces the labor input required to evaluate seedling growth rate and increases the accuracy of these measurements.
\end{abstract}

Keywords: Purity test, Digital Image Processing, MATLAB.

\section{INTRODUCTION}

Seed testing is the cornerstone of all other seed technologies. Seed testing is used for control of quality parameters during seed handling, and test results are submitted to customers as documentation on seed quality. It is the means by which the quality of seed can be measured and viability of seed is ensured. Seed testing is determining the standards of a seed lot namely physical purity, moisture, germination, vigor and thereby enabling the farming community to get quality seeds.

A weed free seed lot is the most efficient strategy to achieve established market standard. Separation of good quality seeds, if done with right equipment and appropriate methods, can increase purity test. It can also help in discarding the number of diseased seeds and can improve the visual, commercial and planting quality of seed lot. Seed quality is essential for maintaining the seed viability for extended periods of time. Knowledge of the seed's physical characteristics may offer an insight on germination levels.

Physical purity analysis tells us the proportion of pure seed component in the seed lot as well as the proportion of other crop seed, weed seed and inert matter by weight in percentage for which Seed Standards have been prescribed. Thus, it helps in:

I. Improving the plant stand (by increasing the pure seed component).

ii. Raising a pure crop (by eliminating other crop seed and weed seeds).

iii. Raising a disease free-crop (by eliminating inert matter).

\section{MATERIAL \& METHODOLOGY}

The research paper was conducted in laboratory of Seed Testing, Nagpur and Seed Technology Research Unit, Department of Botany, College of Agriculture, Akola. Purity test is conducted on various seeds. The purity analysis of a seed sample in the seed testing laboratory refers to the determination of the different components of the purity viz., pure seeds, other crop seeds, weed seeds and inert matter. The objective of the purity analysis is to determine whether the submitted sample conforms to the prescribed physical quality standards with regard to physical components.

Seed physical purity test is the most fundamental and the first test to be carried out in seed testing, as the subsequent tests are made only on the pure seed component. Purity test is sorted out three components; inert matter, other seed and pure seed. Seeds were divided into smaller portion but representing whole seed sample and not bias. Seeds were weight and by using forceps and thin ruler, seeds were divided into various components accordingly pure seeds, other seeds, and inert matter. Finally, each component was weight and percentages of each component were calculated.

There are two phases - training phase and testing phase.

In training phase database of different patterns is created adaptively and manually. 


\section{$>\quad$ Create Database Adaptively}

In adaptive method different patterns can be found by applying different techniques i.e. image pre-processing and image enhancement. These techniques find out the percentage of germination.

Create Database Manually

In manual method different patterns and percentage of germination to those patterns are collected.

$>\quad$ Testing Phase

In testing phase infected patterns can be detect from the database and find the percentage of germination for that patterns.

$>\quad$ Testing Phase for Create Database Adaptively

In this phase take image as an input for which find the different patterns.

Testing Phase for Create Database Manually

In testing phase patterns are loaded from the database. Then pattern and percentage of germination from the list are selected. Discover those patterns and apply fuzzy rule to find the maximum frequency of different patterns. If not satisfied with fuzzy conclusion go to differential pre-processing. The first and foremost step is to draw a true representative sample from the seed lot.

To obtain a random sample for testing it is always best to take samples from different parts of the bag or container.

\subsection{Block Diagram of system}

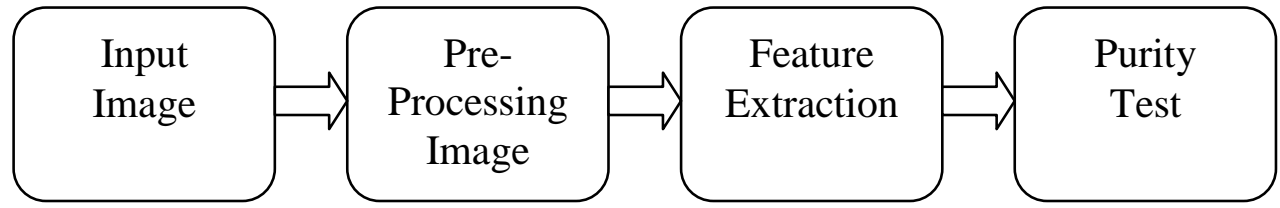

Fig. 1 Block Diagram of System

- $\quad$ Input Test Image

Take an input seed image from seed lot by using digital camera.

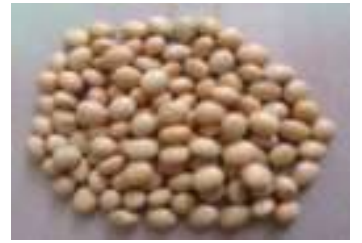

Fig. 2 Input Image

\section{- Image Enhancement}

Image enhancement is the process of adjusting digital images so that the results are more suitable for display or further image analysis. For example, you can remove noise, sharpen, or brighten an image, making it easier to identify key features.

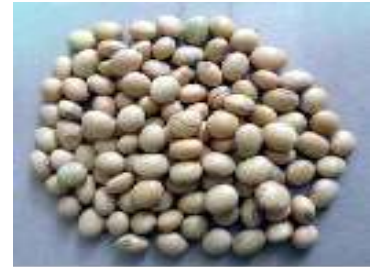

Fig.3 Image Enhance.

\section{- $\quad$ Pre-process Images}

Basically the images which are finding during image acquisition may not be directly suitable for detection and sorting purposes, such as weather conditions, noise and poor resolution. Because of some factors images and unwanted background etc. we always try to approve the well-known techniques. The steps involved in pre-processing are : 
- Input image

- Removing the background

- RGB to Gray conversion

- Gray to Binary conversion Unsharp filtering

- Boundary removal

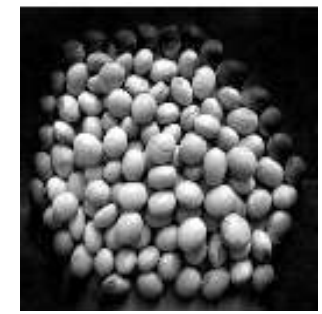

Fig.4 Image Pre-processing

\section{- $\quad$ Feature Extract}

Feature extraction methods extract the distinct features from the images like edges, corner, which can be used to match or discriminate image from other similar image. In developed an algorithm for extraction of color features from bulk seed samples. Generally, the colour, shape, and texture features extracted from the image to recognize an image.

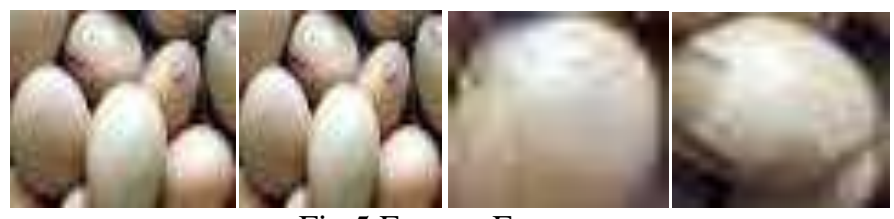

Fig.5 Feature Extract

\subsection{Flow Chart of System}

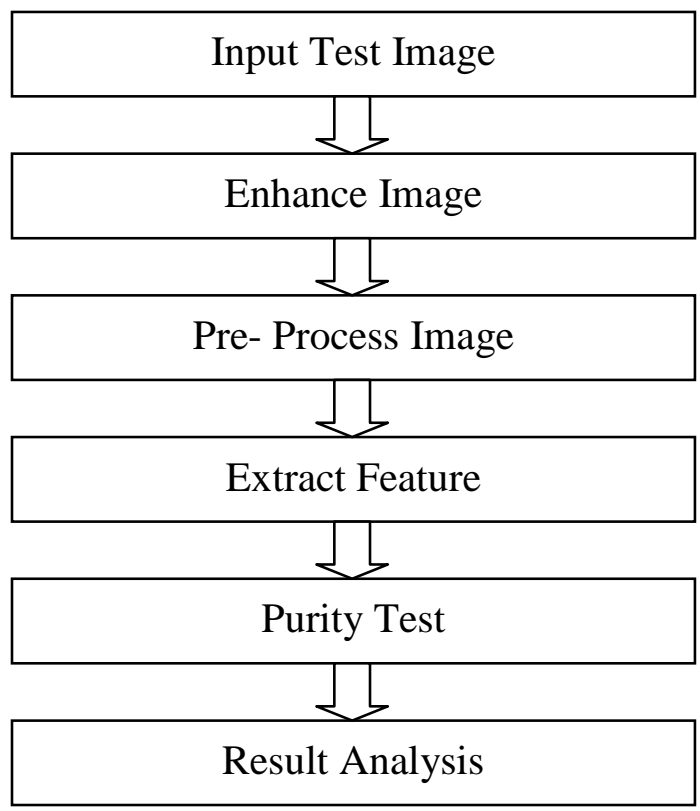

Fig.6 Data Flow Diagram of System

\section{RESULT}

In this paper we are generating the result in two parameters as follow

1. Purity Test

2. Graphical Representation 
International Journal of Innovative Research in Electrical, Electronics, Instrumentation and Control Engineering

ISO 3297:2007 Certified

Vol. 5, Issue 5, May 2017

\section{Purity Test Result}

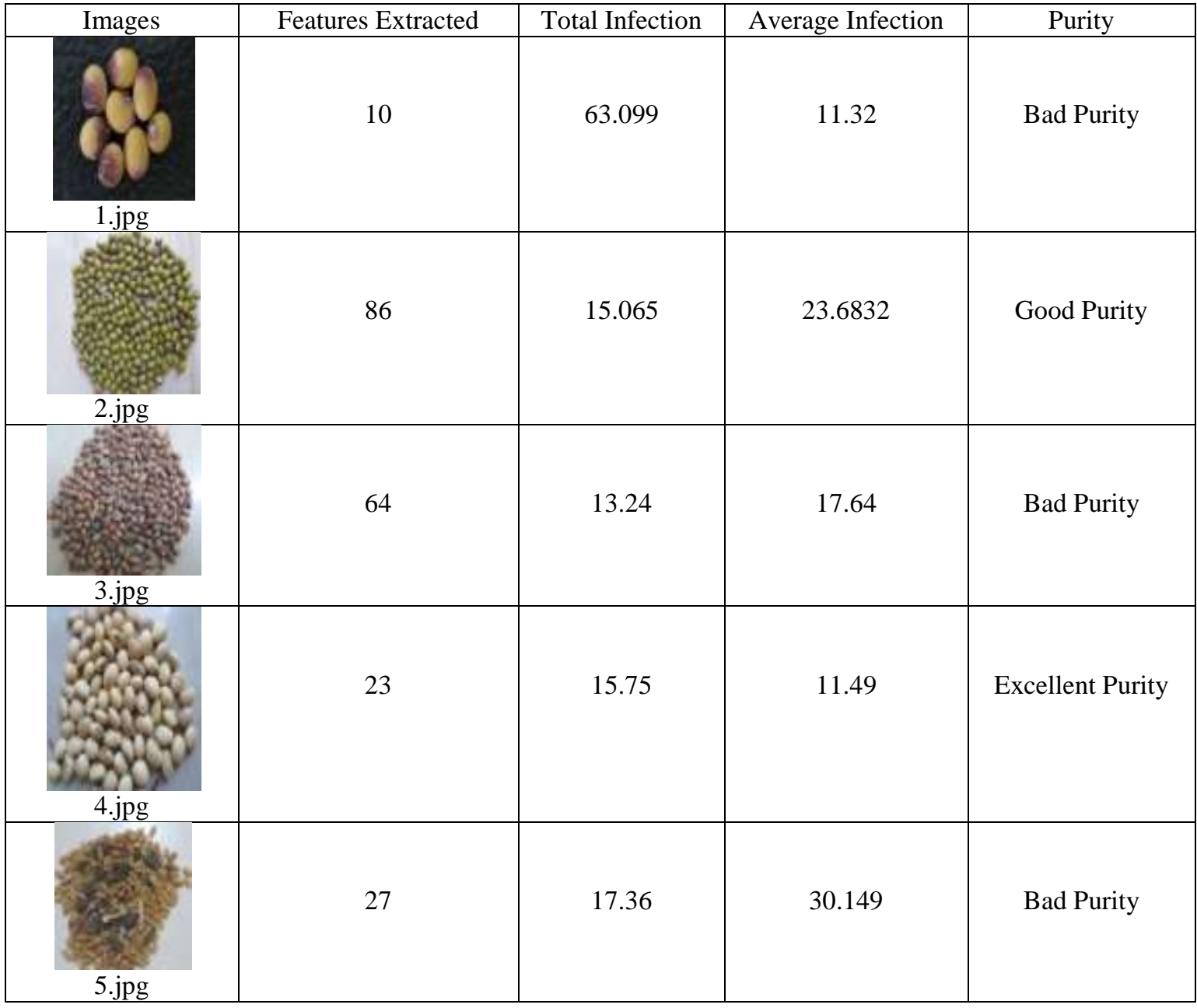

Table.1 Result of Purity Test

1. Graphical Representation

2.1 Feature Extract vs Total infection vs Average Infection

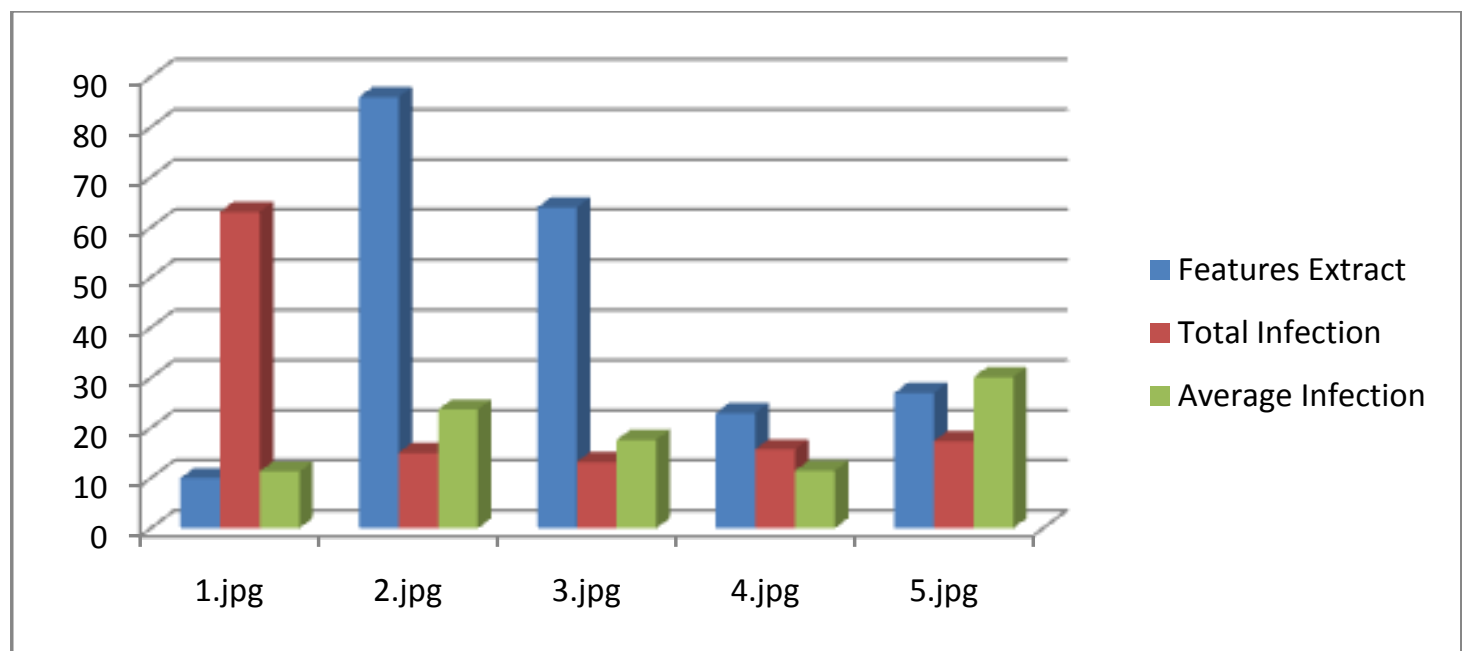

Graph.1 Feature Extract vs Total infection vs Average Infection 


\section{IJIREEICE

\section{CONCLUSION}

This paper describes the survey of different Digital image processing techniques for seed purity evaluation. It describes how the imaging technology is applied in monitoring seed imbibitions, purity behavior and analysis of seed size, shape parameters. Recently, the greatest efforts have focused on producing nondestructive methods with capability of computer hardware of image processing and its integration with controlled environmental condition systems. New algorithms and hardware architectures have been developed, and the availability of appropriate image analysis software tools suggests that the use of Digital image processing systems is becoming convenient in a seed biology laboratory.

\section{ACKNOWLEDGMENT}

I express my deep sense of gratitude and sincere regards to my Guide Prof. Dr. S.V. Rode. His timely guidance and helpful discussions has supported me immensely in selecting a new proposal and completing dissertation work. Finally, I would like to thank all Professors and my colleagues who directly or indirectly helped me during my work.

\section{REFERENCES}

[1] Seed Vigor Testing Handbook, AOSA. Contribution No. 35, 1992, pp. 101

[2] Guide to Handling of Tropical and Subtropical Forest Seed' Chapter 11, Seed Testing, by Lars Schmidt, Danida Forest Seed Centre, 2000.

[3] 'Seed Technology', 2nd Edition, by Rattan Lal Agrawal, Oxford \& IBH Publishing Co. Pvt. Ltd. New Delhi. 2004

[4] Y. Sako, M. B. McDonald, K. Fujimura, A. F. Evans, and M. A. Bennett, 'A System for Automated Seed Vigor Assessment', 2001.

[5] A.L. Hoffmaster, K. Fujimura, M.B. McDonald, M.A. Bennett, 'An Automated System for Vigor Testing Three-Day-Old Soybean Seedlings', 2003.

[6] Robert L. Geneve, Sharon T. Kester, 'Evaluation of Seedling Size Following Germination Using Computer-aided Analysis of Digital Images from a Flat-bed Scanner', HortScience 36(6): 1117-1120, 2001.

[7] K. Oakley, S. T. Kester, R.L. Geneve, 'Computeraided Digital Image Analysis of Seedling Size and Growth Rate for Assessing Seed Vigor in Impatiens', Seed Sci. \& Technology, 32, 907-915, 2004.

[8] M. S. Howarth, P.C. Stanwood, 'Measurement of Seedling Growth Rate By Machine Vision', Emerging Technologies Div. of ASAE, Vol. 36(3): 959-963, May-June 1993.

[9] A. Dell'Aquilla, 'Application of a Computer- Aided Image Analysis System to Evaluate Seed Germination under Different Environmental Conditions', Ital. J. Agron., 8, 1, 51-62, 2004.

[10] Chao Li, Amar Raheja, and David W. Still, 'Application of Computer Vision for Lettuce Seeds Germination Detection'.

[11] Antonio Dell'Aquilla, 'New Perspectives for Seed Germination Testing Through Digital Imaging Technology', The Open Agriculture Journal, 2009. 